\title{
Towards building an integrated urban water system model to inform the identification of optimal water source mixes for Adelaide
}

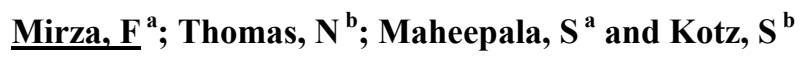 \\ ${ }^{a}$ CSIRO Land and Water, ${ }^{b}$ South Australian Water Corporation \\ Email:fareed.mirza@csiro.au
}

\begin{abstract}
The South Australian Water for Good Strategy outlines the actions that are required to ensure South Australia's water supplies are secure, safe, reliable and able to sustain continued growth. It supports diversification of supplies to reduce the reliance on rain-dependant sources. A study has been initiated by the Goyder Institute for Water Research in this regard, in particular to inform the identification of optimal mixes of water sources for metropolitan Adelaide. As part of this study an integrated system simulation model of metropolitan Adelaide's water system is being developed. This is to quantify supply implications and stormwater and wastewater discharges at defined points in the urban water system, when utilising different mixes of water sources, under both historical and future climatic conditions. This information is used to evaluate an objective function that aims at minimising life cycle cost of infrastructure, energy consumption and the potential impact on Adelaide's coastal waters, and maximising supply security, as part of a multiobjective optimisation based decision-support framework. The aim of the decision-support framework is to generate knowledge that can support the identification of the most cost-effective mix of fit-for-purpose water sources available to meet the needs of the community in metropolitan Adelaide, in an environmentally and financially sustainable manner. The sources to be considered are River Murray, surface water from Mount Lofty Ranges catchments, desalinated sea water, recycled wastewater, stormwater including roof water, ground water and the potable water savings through various demand management options. The objective of this paper is to describe the process followed to develop the simulation component of the combined simulation-optimisation approach.
\end{abstract}

The modelling platform used to develop the simulation model is Source Integrated Modelling System (IMS), which is emerging as Australia's national hydrologic modelling platform for river basins. Hence it has not been applied widely yet, particularly for urban water systems. The study reported in this paper one of the first application of eWater Source to urban water systems. The application process has been an exploratory process where modelling methods have to be developed for the each water source considered in this study using the available functionalities. Also, there are modelling methods currently in place in most cities to inform planning and operation of each city's water supply system. In general, when a new modelling method is introduced, quantitative evidence is required to demonstrate the performance of the new methodology is comparable to that of the existing methodology. Thus the process to develop the simulation component of the simulation-optimisation approach was staged and comprised the development of firstly a Test Case, secondly a Base Case before developing the Scenario Cases. In this paper, we describe the Test Case and the Base Case. Development of Scenario Cases is in progress. The purpose of the Test Case is to examine the ability of the eWater Source to represent key features of metro Adelaide's water supply system, to an adequate level. The 'adequacy' was defined as the ability of eWater Source to generate outputs (e.g. pumping volumes and storage volumes) of a similar order of magnitude from an existing water supply planning and operation model that is currently used by the South Australian Water Corporation. The Base Case model represents the 'business as usual' scenario for supplying water from the three main drinking water supply sources for Adelaide, i.e. River Murray, Mount Lofty Ranges catchments and Adelaide Desalination Plant. The simulation is performed over 50 years, on a monthly basis. The optimisation time horizon is 25 years, from 2013. The simulation model is provided with functionalities using the Expression Editor capability in the eWater Source to evaluate the objective function, consisting of net present value of life cycle cost of infrastructure, energy consumption and the volumetric reliability of supply. Development of Scenario Cases is in progress, which will include adding the other sources mentioned above. The Scenario Cases will also provide information to minimise potential impact of wastewater and stormwater discharges to Adelaide's coastal waters. The results of the Test Case showed that eWater Source can adequately represent the existing water sources in Adelaide's water supply. The results of the Base Case showed that eWater Source can produce the expected behaviour of the supply system. The project is in progress.

Keywords: Adelaide, eWater Source, Optimal Water Mix, Integrated system modelling, Urban water 


\section{INTRODUCTION}

The public water supply side of the urban water cycle in metropolitan Adelaide draws on a diverse network of sources including surface water from a mix of ten different reservoirs spread throughout the local Mount Lofty Ranges (MLR) catchments with supplementary water from the River Murray, and more recently (since late 2011) desalinated seawater from the Adelaide Desalination Plant (ADP). Adelaide's urban water cycle also features $26 \%$ of recycled wastewater use, which is the highest amongst Australian utilities (National Water commission, 2013), and 6\% stormwater recycled, in order to reduce discharges to the Gulf St. Vincent. Continuation of the traditional practice of urban water management in metropolitan Adelaide has been challenged in recent years. This is due to a number of emerging needs for ensuring: (a) water security for a growing urban population in a changing climate, which is predicted to be drier and warmer than the historical climate (Government of South Australia, 2007), (b) healthy inland waterways and coastal waters (Government of South Australia, 2013), and (c) liveable and productive urban environments (Government of South Australia, 2010a). The South Australian Government has identified integrated urban water management (IUWM), as a possible solution to address these needs. The government's commitment to implement integrated urban water management principles has been demonstrated through the actions identified in the Water for Good Strategy and the 30 Year Plan for Greater Adelaide (The Government of South Australia, 2010b), as well as an initiative to integrate water and recycled wastewater planning (called the 'Urban Water Blue print') for metropolitan Adelaide.

A number of projects have been initiated by the South Australian Government through the Goyder Water Research Institute, a partnership between the universities based in South Australia and the CSIRO Australia, to inform the development of the Urban Water Blueprint. One such project is the Optimal Water Resource Mix (OWRM) project, which is the focus of this paper. The objective of this project is to generate knowledge that could support the identification of the most cost-effective mix of fit-for-purpose water sources available to meet the needs of the community in metropolitan Adelaide, in an environmentally and financially sustainable manner. Environmental sustainability is addressed by examining ways to minimise energy consumption and discharges to the Gulf St Vincent. The sources to be considered are River Murray, surface water from MLR, desalinated sea water, recycled wastewater, stormwater (including roof water), ground water and the potable water savings through demand management options. The overall approach adopted is integrated systems analysis, which combines IUWM principles (Maheepala et al., 2010; Burn et al., 2012) with the systems analysis approach, an approach widely used to inform water resources planning (Loucks et al., 1981; Loucks and van Beek, 2005). The systems analysis techniques used in the OWRM project are multi-objective optimisation and simulation. These two techniques have been used both as standalone approaches and as a combined approach in the past, for water supply systems with multiple reservoirs to inform both long-term and operation planning (Labadie, 2004; Rani and Moreira, 2010). In the OWRM project, a combined simulation-optimisation approach has been adopted to search for the solutions that have the potential to best meet the above-mentioned objective.

The objective of this paper is to describe the process followed to develop the simulation component of the combined simulation-optimisation approach. The key challenge associated with simulating the behaviour of the urban water system in a total water cycle management planning context is the need to represent the whole urban water system from supply catchments to receiving waters including water supply, wastewater, stormwater, recycled and reuse water and receiving water systems and the interactions among these subsystems. This challenge becomes further complicated by the need for coupling it with an optimisation component, in order to adopt a combined simulation-optimisation approach that can identify the optimal portfolio of water sources at a city scale, i.e. metropolitan Adelaide. This means the simulation methodology should be able to represent the whole urban water system and simulate behaviour of the urban system with sources that operate at multiple scales ranging from household rainwater tanks to centralised desalinated water, by considering interactions between the supply, consumption and discharge to receiving waters. The complexities of the urban water cycle mean that this modelling exercise is data intensive and must adapt where data is unavailable or due to poor quality. In this paper, we will describe the process followed to develop the simulation methodology and discuss the results thus far.

\section{METHODOLOGY}

The OWRM project used a combined simulation-optimisation approach to identify the optimal mix of water sources in terms of a defined objective function. The objective function of the optimisation was designed to: minimise infrastructure life cycle costs and energy consumption, maximise supply security and minimise stormwater and wastewater discharges to Adelaide's coastal waters, by considering the needs of the Adelaide community in terms of water supplies. This paper focuses on the simulation and not the optimisation. The 
purpose of the simulation was to generate information to evaluate the objective function. The required information from the simulation component involved supply security, discharges to Adelaide's coastal waters and water flows at defined locations, life cycle costs of the infrastructure and the energy consumed through operation of the infrastructure, for different mixes or portfolios of water sources.

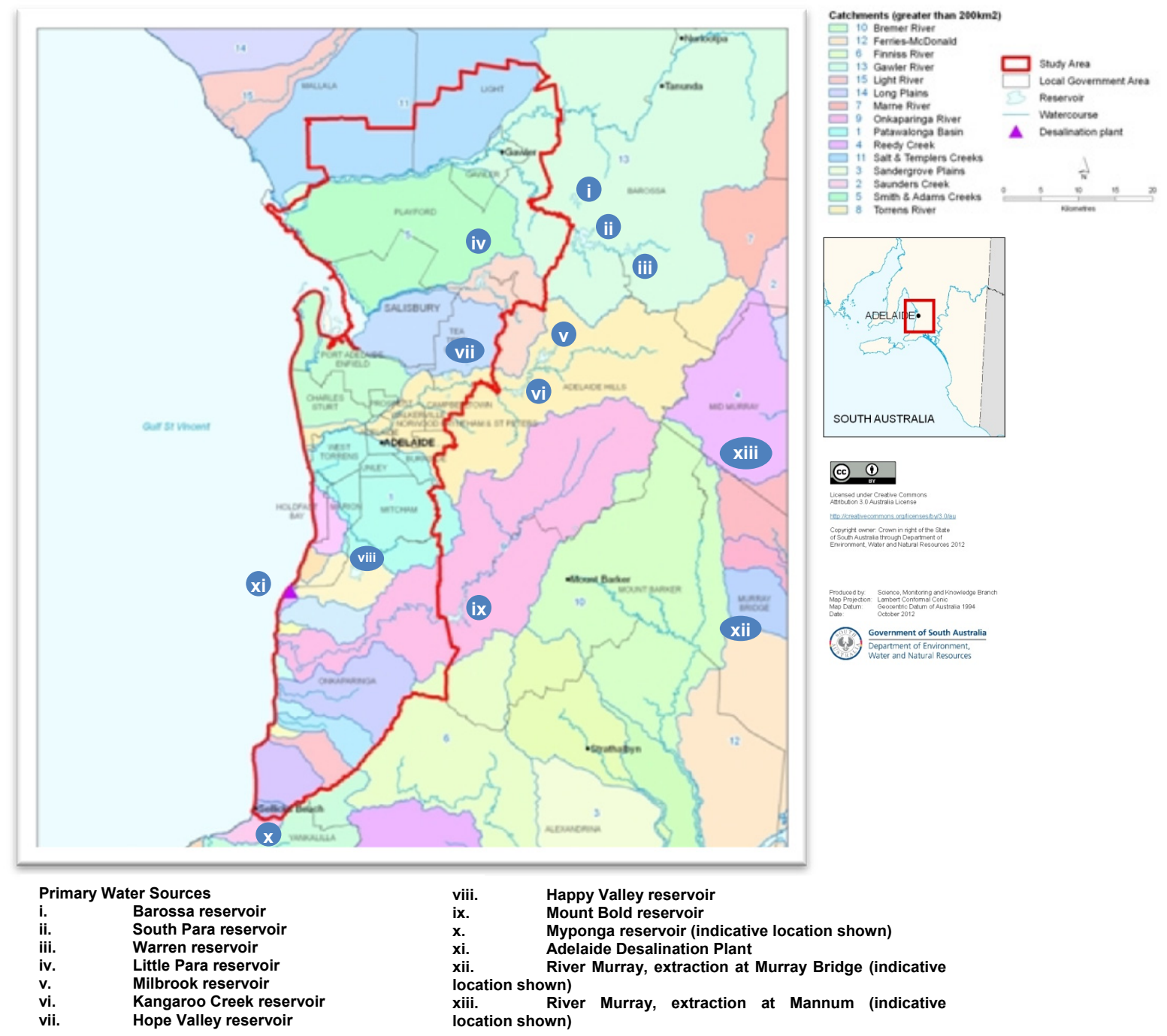

Figure 1 Study area (red polygon) and primary water sources

The spatial extent to be considered for the simulation (i.e. study area) was metropolitan Adelaide. It included the area extended from the Gawler local government area (including Concordia and Roseworthy growth areas) in the north, to south of Myponga reservoir, and from the foothills of Adelaide Hills in the east to Adelaide's coast (Figure 1). It should however, be noted that some sources were located outside of the study area, e.g. River Murray extraction locations and some MLR storages.

An appropriate simulation method was sought by considering the purpose of undertaking simulation and the spatial extent of simulation. An emphasis was given to a simulation method that could be easily coupled with an appropriate optimisation method, and represent both runoff and nutrient generation and transportation from urban catchments, along with supply from multiple sources, particularly from such sources as stormwater and recycled wastewater. In addition, consideration was given to a modelling method that could be either used by the stakeholders as a decision support tool to inform the development of urban water management policy tools upon completion of the project, as well as being considered by the stakeholders to meet future water management needs. The simulation methods that best fit these criteria were WaterCress (Clark et al. 2002) and Source Integrated Modelling System (eWater, 2012). Both models had the technical capacity to meet the simulation needs mentioned above. However, when considering future modelling needs, eWater Source met the future needs better than the WaterCress model, because, eWater Source: (a) included a flexible structure to select a level of model complexity appropriate to the problem at hand and within any constraints imposed by the available data and knowledge (eWater, 2012); (b) is being considered as the 
National Hydrologic Modelling Platform by the Australian Government as part of the National Water Initiative; (c) is being supported by the South Australian Government as part of their commitment to the National Water Initiative through its utilisation where appropriate, and investing in further development of the tool with an aim of creating a community of practitioners and resources for a common interest to enable capitalising on the investment made to develop the modelling tool; and (d) being maintained and supported by an organisation supported by the Australian Government (www.ewater.com.au). Hence eWater Source was chosen as the preferred method for the simulation, as eWater Source is an emerging modelling platform for river basins, it has not been applied widely yet, particularly for urban water systems. Hence the study reported in this paper is one of the first applications of eWater Source to urban water systems. The application process has been an exploratory process where modelling methods have to be developed for the each water source considered in this study using the available functionalities. Details of the eWater Source can be found in (eWater, 2012).

The process to develop the simulation component of the simulation-optimisation approach was staged and comprised the development of firstly a Test Case, secondly a Base Case before developing the Scenario Cases. In this paper, we describe the Test Case and the Base Case. Development of Scenario Cases is in progress.

\subsection{Test case}

The purpose of the Test Case was to examine the ability of eWater Source to represent key features of metro Adelaide's water supply system adequately. The key features included pumping from the River Murray, catchment and environmental flows, urban water demand, pipe infrastructure, storing water in off-stream storages, and supplying from a desalination plant. 'Adequacy' was defined as the ability of eWater Source to generate outputs (e.g. pumping volumes and storage volumes) of a similar order of magnitude from an existing headworks model that is currently used by South Australian Water Corporation (SA Water). To be considered successful, the Test Case developed in eWater Source was required to successfully output comparable results. The output of similar results was important to gain confidence in eWater Source's ability to recreate key features of the system and be considered as a viable modelling platform for the next stage of modelling Adelaide's urban water system; the multi-objective optimisation.

SA Water currently uses a specialised simulation model for supply planning, called HOMA: Headworks Optimisation Model for Adelaide (Crawley and Dandy, 1993). HOMA is a monthly time-step optimisation model, used for planning of major pumping from the River Murray and other pipeline transfers. The model represents the headworks system as a series of equations and uses linear programming to find the optimal solution that minimises operating cost subject to meeting the demands and maintaining minimum target storage levels. The inputs to the Test Case were specially generated by SA Water and applied to both eWater Source and HOMA. In this regard, all results produced were valid for relative comparison and not indicative of actual performance of the Adelaide's water supply system. The Test Case developed in eWater Source had seven demand centres, thirteen surface storages/weirs, two water treatment plants, three points of extraction from river, eleven inflows points and the one desalination plant. The model was populated with monthly data for the ten year period $1 / 7 / 1998$ to $1 / 6 / 2008$.

Extraction of water from the River Murray was modelled as an infinite capacity storage node with no rainfall on or evaporation from the surface, and a defined capacity valve on the release link downstream of the storage. The valve capacity represented the capacity of pumps at the extraction location. Surface water sources from the MLR were modelled as finite capacity storages with a downstream link from the each storage to force releases to meet a defined environmental flow requirement. The desalination plant was modelled as an infinite capacity storage node, similar to the extractions from the River Murray. The valve on the release link downstream of the desalination source node represented the production capacity of the desalination plant. Inflows to the surface water sources from the MLR catchments, and the water demands were provided as inputs (monthly time series covering the simulation period) to the eWater Source. Results of the Test case are described in Section 3.

\subsection{Base case}

This represents the 'business as usual' scenario for supplying water from the three main drinking water supply sources. The sources included in the Base Case were River Murray, MLR and ADP. A change from the Test Case was the aggregation of the surface water reservoirs in the MLR to three and the seven demand zones in the Test Case were aggregated to three demand zones. This rationalisation of the network was done to allow for: (a) capturing the current thinking by SA Water on the representation of demands and sources, 
and (b) reducing the level of interaction between many smaller storages and demand zones, which was considered to be adding an unnecessary complexity to the problem being addressed by the OWRM project.

A schematic diagram of the Base Case is shown in Figure 2. The three storages were: Gawler, which represented the lumped storage of Warren, Barossa and South Para reservoirs; Torrens, which represented the lumped storage of Millbrook, Kangaroo Creek and Hope Valley reservoirs and Gumeracha and Torrens Gorge weirs; and Onkaparinga, which represented the lumped storage of Mount Bold and Happy Valley reservoirs and Clarendon weir. The combined capacity of the three surface water storages was 171 GL. Releases from the storages were governed by the monthly target storage levels, which were specified as an input. The extractions from the River Murray were provided to the system via three pipelines: MannumAdelaide pipeline (capacity $364 \mathrm{ML} / \mathrm{d}$ ), Murray Bridge-Onkaparinga pipeline (capacity $510 \mathrm{ML} / \mathrm{d}$ ) and Swan Reach-Stockwell (SRS) pipeline (capacity $79 \mathrm{ML} / \mathrm{d}$ ). The capacity of the Adelaide Desalination Plant (ADP) was $300 \mathrm{ML} / \mathrm{d}$. Treatment costs were considered as part of the multi-objective optimisation, and included in the simulation model. The three demand zones were: Northern, Central and Southern, which represented urban water demand of the study area, shown in Figure 1. The boundaries of these demand zones followed the boundaries of South Australian government regions. The central demand was an aggregation of the eastern and western Regions.

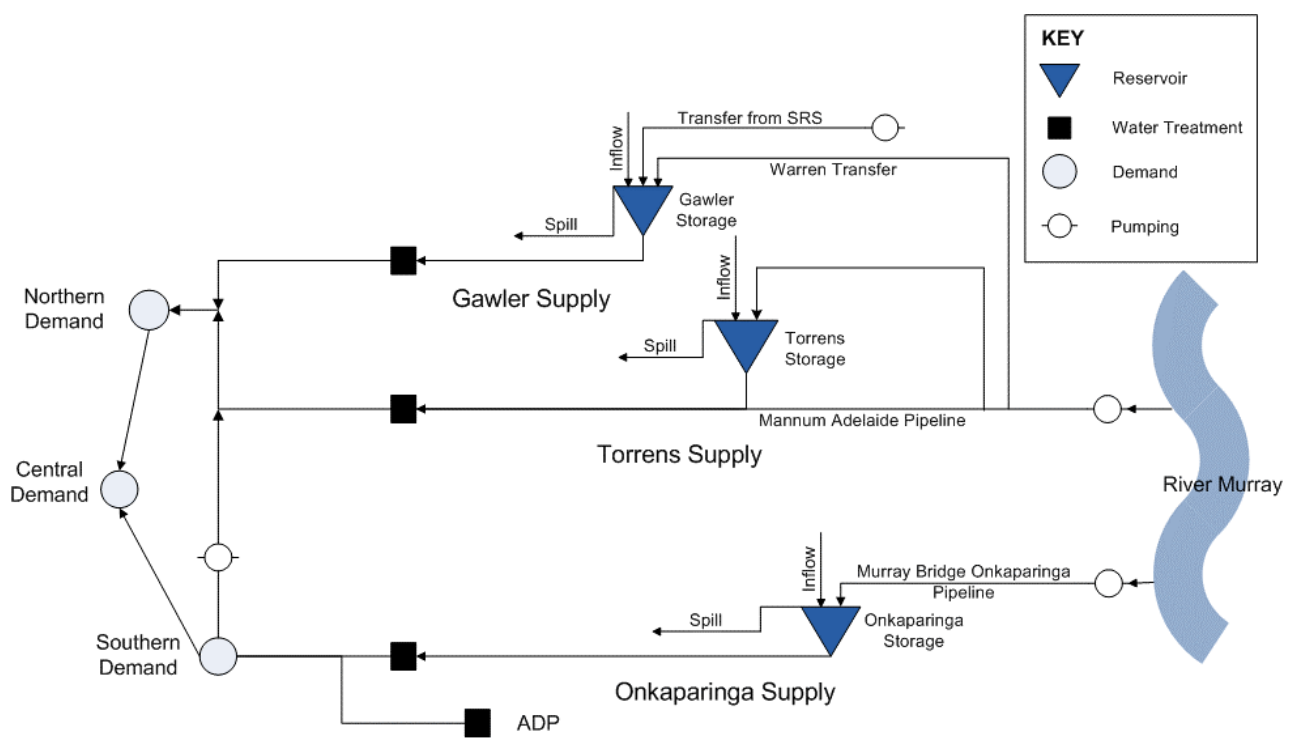

Figure 2 Schematic diagram of the Base Case

This eWater Source was user configured to use Network Linear Programming (NLP), one approach available in eWater Source, to determine the optimal flow volumes to be allocated from each source to meet each demand in each time-step of the simulation. In NLP, the order of supply, as well as the amount supply from the sources to demands was controlled by 'penalty costs' assigned to appropriate nodes and links. Given the purpose of simulation was to evaluate an objective function defined for the optimiser, the penalty cost values were controlled by the optimisation, with an aim of determining the best mix of water sources to meet the given water demand.

The modelling approach adopted for the three sources was the same as the approach described in Section 2.1. The target storages were modelled by defining appropriate penalty costs: one for above and one for below the target storage for each time-step. The extractions from the River Murray were subjected to a limit of $650 \mathrm{GL}$ over five years. This was modelled by using a global variable that kept track of the volume of water pumped from the three river sources. The running total was checked against this configured limit of $650 \mathrm{GL}$ over five years. If the limit was breached, a Maximum Order Constraints node downstream of each point was effectively closed off by assigning its capacity a value of ' 0 '.

The simulation was performed over a period of 50 years, from 1/7/1963 to 1/6/2013, on a monthly basis. Inflows for the three storages were sourced from SA Water. The WAPABA (Water Partition and Balance) model (Wang et al., 2011) was used to extend the inflows for the simulation period. This was a monthly water balance model, for predicting monthly streamflows based on monthly rainfall and potential evapotranspiration (PET). Extending inflow records for the simulation period involved calibrating and validating the WAPABA model using the observed data, and generating monthly inflows over the period of fifty-year period using the calibrated model. Rainfall and PET data from Williamstown, Millbrook and 
Mount Bold Reservoir were used for generating the inflows to Barossa, Torrens and Onkaparinga storages, respectively.

A multiple linear regression model was used to develop water demands for the three demand zones over the simulation period, by considering the effect of climate on water demands. To keep this process simple it was assumed that the defined relationship would hold under a future climate conditions and future population growth and changing population densities. The key climate factors used in the past by SA Water were temperature (using Cooling Degree Days) and rainfall. The Base Case used this process to adjust the demand so that the time series was representative of the 2012/13 level of demand. A climate relationship for the simulation period was established by using SA Water's $\mathrm{CDD}_{12}$ multiple linear regression relationship.

The Base Case model was developed with an aim of identifying trade-offs between three objectives, i.e. minimise lifecycle cost of infrastructure, minimise energy consumption and maximise supply security, over a twenty-five year period, from 1/07/2013. The objective function was evaluated within the simulation model. Expression (renamed Function in latest version of eWater Source) Editor functions (Kim, 2011) were used to develop the objective functions within the eWater Source. The value of the objective function was made visible to INSIGHT, the optimisation module of eWater Source. Given the Base Case model had only existing sources, the life cycle cost included operation and replacement costs only. It was assumed that the existing treatment, pumping, distribution and desalination infrastructure would not need to be replaced over the next twenty-five years. Hence the objective on life cycle cost minimised the net present value of the total operation cost, which included energy consumption associated with the treatment, pumping and desalination. The parameter used for evaluating the supply security was volumetric reliability, which was defined as the proportion of the total demand supplied by the sources.

\section{RESULTS AND DISCUSSION}

The Test Case compared the outputs of HOMA and eWater Source models, at different points in the system, but of primary concern was the total volume pumped from the River Murray and maintenance of target storage levels. The total volume pumped from the River Murray was found to vary by only $3 \%$. However, the volumes pumped from each of the three pumping locations: Mannum, Murray Bridge and Swan Reach, were found to vary from $-50 \%$ to $+40 \%$ (- for under-extraction and + for over-extraction). This was due to the use of the North-South network transfer in the test model, which had no costs associated with it, as opposed to how it's modelled in HOMA, and therefore, eWater Source used it to supply water from south to north of Adelaide resulting in more extractions from Murray Bridge. The model counter-balanced this by extracting less from the other two locations, resulting in a comparable output with regard to the volume pumped from the River Murray. This can be overcome by using a Parallel Arc node in eWater Source to add a penalty that impacts the NLP solution.

eWater Source was equipped with required functionalities (i.e. penalty costs as part of NLP approach) to release water from reservoirs by taking into account such constraints as monthly target volumes. Hence the target storage levels were found to be maintained as required, which resulted in comparable overall storage volumes, particularly after the first few years of the simulation. The deviations observed during the first few years were due to the difference in solving methods used by the two models for supplying water from multiple sources (described below). It should also be noted that eWater Source does not have links with configurable capacities seen in other platforms, such as HOMA or REALM (Perera and James, 2003). To achieve a similar outcome, a combination of release mechanisms (e.g. valve, pump, culvert models) had to be assigned to links exiting a 'Storage node model' and 'Maximum Order Constraints node models', which were some of the functionalities provided in eWater Source.

One of the key differences between the two models was the solving method for determining the volume of water to be supplied from each source in the presence of multiple sources. HOMA used a linear programming approach, which solved the problem by considering 'optimality' over multiple time-steps. In contrast, eWater Source used a NLP approach, which solved the same problem by considering 'optimality' over a single timestep. This made comparison of outputs of the two models a difficult task, however by identifying key management variables, total volume pumped and maintaining of target storage levels, this was achieved to an acceptable level. Hence the task of replicating the Adelaide's water supply system in eWater Source involved making decisions at different points on how best to describe the system using the functionalities offered by the eWater Source. The key learning from the Test case was that comparison of outputs of two structurally different modelling platforms would need a degree of expertise to be applied to the outputs, to assess if they are acceptable as a representation of a physical system being studied. 
In order to test the performance of the Base Case, three scenarios were considered by manually assigning penalty costs: the first scenario assigned penalty costs to give the highest preference to surface water from the MLR, then to River Murray and the lowest preference to ADP; and the second and third scenarios used the same penalty costs, but the total demand was increased by twofold and threefold respectively, compared to the first scenario. The proportion of water supplied from the MLR, River Murray and ADP to meet the demand fully was: for the first scenario, $66 \%, 27 \%$ and $7 \%$ respectively, for the second scenario $37 \%, 36 \%$ and $27 \%$ respectively; and for the third scenario, $32 \%, 38 \%$ and $30 \%$ respectively. As expected, the results indicated that most of the current demand could be met with the surface water from the MLR and pumping from the River Murray. However, when the demand was increased, more desalinated water would be required to meet the demand fully. The outputs showed the expected result, which was considered adequate, in order to use the simulation model in conjunction with a genetic-algorithm based optimisation approach to examine the best proportion of water supply from multiple sources.

\section{CONCLUSION AND NEXT STEPS}

The eWater Source had sufficient functionalities to represent Adelaide's current water sources: River Murray, MLR and the ADP. The Test Case demonstrated that the eWater Source could adequately predict the behaviour of Adelaide's supply system. The business-as-usual case showed that if the demand was increased, the proportion of water supplied from the desalination plant would have to be increased because of the limited availability of water from the MLR and the River Murray. The project is in progress to add stormwater, rainwater, recycled wastewater and groundwater as sources of supply. The relationship between the researchers and the state water utility is one of the successful outcomes of this project and has helped facilitate access to data and interpretation of the local issues impacting the Adelaide public water supply system.

\section{ACKNOWLEDGMENTS}

We would like to thank SA Water, for providing us with all the data to populate the eWater Source model. We would also like to thank The Goyder Institute for Water Research for providing the funds to undertake the study. The cost and energy data have been provided by Professor Graeme Dandy and his team at the University of Adelaide, who are responsible for formulating the optimisation component.

\section{REFERENCES}

Burn, S., Maheepala, S. and Sharma, A. K. 2012. Utilising integrated urban water management to assess the viability of decentralised water solutions, Journal of Water Science and Technology, 66.1, International Water Association.

Clark R., Pezzaniti D.and Cresswell D. 2002. Watercress - Community Resource Evaluation and Simulation System - A tool for innovative urban water system planning and design, Proc Hydrology and Water Resources Symposium 2002, 20-23 May, Melbourne.

Crawley, P.C. and Dandy, G.C. 1993. Optimal Operation of a Multiple Reservoir System. Journal of Water Resources Planning and Management, ASCE, 119 (1), 1-17, January.

eWater. 2012. User Guide for Source 3.1.0 - 22 August 2012, www.ewater.com.au

Government of South Australia. 2013. Adelaide Coastal Water Quality Improvement Plan (ACWQIP), EPA, South Australia, http://www.epa.sa.gov.au/xstd files/Water/Other/acwqip final.pdf

Government of South Australia. 2010a. The 30-year plan for Greater Adelaide. Department Planning and Local Government.

Government of South Australia. 2010b. Water for Good: A plan to ensure our water future to 2050.

Government of South Australia. 2007. Climate Change in the Adelaide and Mount Lofty Ranges Region, Adelaide and Mount Lofty Ranges Natural Resource Management Board, http://www.prospect.sa.gov.au/webdata/resources/files/Climate Change Brochure.pdf

Kim, S., Dutta, D.,Singh, R.,Chen, J. And Welsh, W. 2011. Providing flexibility in GUI-based river modelling software: Using Expression Editors and plug-ins to create Custom Functions in eWater Source, MODSIM 2011, International Congress on Modelling and Simulation, Perth, Australia, pp. 2345-2351.

Labadie J. W. 2004. Optimal operation of multireservoir systems: state-of-the-art review. J Water Resour Plan Manage-ASCE 130(2):93-111

Loucks D.P., van Beek E. 2005. Water resources systems planning and management: an introduction to methods, models and applications. UNESCO, Paris.

Loucks D.P., Stedinger J.R., Haith D.A. 1981. Water resource systems planning and analysis. Prentice- Hall, Englewood Cliffs

Maheepala, S., J. Blackmore, C. Diaper, M. Moglia, A. Sharma and Kenway, S. 2010. Integrated Urban Water Management Manual, Water Research Foundation, 6666 West Quincy Avenue, Denver, CO 80235-3098, USA.

National water commissio. 2013. National performance report 2011-12: Urban utilities. Australian Government.

Perera, B.J.C. and James. B. A. 2003, Generalised Water Supply Simulation Computer Software package, Hydrology Journal, Institution of Engineers (India), 26/1-2, 67-83.

Rani, D. and- Moreira, M. M. 2010. Simulation-Optimization Modeling: A Survey and Potential Application in Reservoir Systems Operation, Water Resour Management 24:1107-1138.

Wang, Q. J., Pagano, T. C., Zhou, S. L.,Hapuarachchi, H.A.P., Zhang, L. and Robertson, D. E. 2011. Monthly versus daily water balance models in simulating monthly runoff, Journal of Hydrology 404 (2011) 166-175. 